\title{
Cottage Industry at NewLink
}

\author{
K.M.S.Barnes, R.W.Jotham, C.I.G. Sherman \\ Department of Adult Education, University of Nottingham
}

\begin{abstract}
This paper outlines the design and development of a computer communication system for an education and training project for people with physical disabilities in the East Midland Region of England. The emphasis is not merely upon the technical development itself but upon the need of technical developments for people with physical disabilities to be created with consideration being given to the social context in which these individuals live. If such considerations do not take place there will be an increasing number of people with physical disabilities who do not have access to these new forms of communication.
\end{abstract}

\section{Introduction}

The Department of Adult Education at the University of Nottingham has been delivering courses in Information Technology to people with a physical disability for 7 years. It has a special project in this area called the NewLink Project. At present this consists of a federation of training projects and proto-enterprises in the East Midland region of England. The project has received funding from national and local government, the Leverhulme Trust, the British Council, the Gulbenkian Foundation and the European Social Fund including the Horizon and Euroform initiatives.

The project is currently delivering education and training to approximately 300 people each year. There is no charge for physically disabled adults and all courses incorporate the use of computer technology. The courses offered range in content from office skills to music composition.

\section{The Social Context}

Through this work it has been found that at present the high cost of Rehabilitation Technology (RT) has led to a polarisation of IT users with a physical disability. The vast majority have little or no access to IT, whilst a small minority have been able to obtain the latest technology by using private funds or applying to charities etc. This minority are also those most likely to have benefited from a better education, who are therefore likely to obtain employment; consequently they are more capable of earning enough to purchase further RT products. This is a further manifestation of the situation described on page 14 of the March edition of the Commission of the European Communities, TIDE 1993-1994 Workplan.

These consumers, particularly disabled people of working age are caught in a vicious circle whereby a lack of $R T$ provision, training and high prices, means that they are not enabled to contribute to the community by working. 
It is evident from the factors mentioned above that, what is needed is the creation and successful distribution of training and products that will go some way to off-setting this historical situation.

This context has formed the backdrop for the research that has been carried out alongside the courses offered by the NewLink Project. One such piece of research has been sponsored by the Leverhulme Trust and has attempted to assess the applicability of computer communications to the lives of physically disabled adults. This research has moved through a variety of stages and has attempted a number of different applications of computer communications. Perhaps the most significant of these has been the development of a simple system based around IBM PC compatible computers which enables tele-working and incorporates tele-training. This work has always had the intention of extending the services offered to adults with a physical disability in their homes and has been conducted under the general name "Cottage Industry At NewLink" (CIAN).

\section{CIAN the System}

The development of this system had its beginning in the setting up of Bulletin Board System (BBS) in August 1990. It was linked to a number of other Bulletin Board Systems around the world, on the FIDONET network. These links were paid for by the Chatback Trust, which is a charity set up to assist disabled people.

As the various implementations of the BBS were tested, a number of regular informal discussions with a variety of disabled individuals were held. The topics covered ranged from the possible activities that could be assisted by CMC, to what sort of equipment was best to buy. From these discussions it was decided to create a system that would allow people with a disability to work and train from home without incurring any extra cost to them.

To keep the cost of the system to a minimum it was decided to write our own controlling software, and to use a shareware program for the communications. The controlling software would present a simple user interface which would then use the communications software to carry out the necessary phone calls etc.

The first steps in writing the software for this system started in August of 1991 and took about four months to complete. This was followed by initial tests of the whole system at the end of 1991. In early 1992, new problems emerged, which were eventually resolved and in November 1992 the system was installed in several users' homes and more tests were carried out. In January 1993 the system was released to the NewLink-Nottingham workshop for the reception of work done at home by workshop members.

A further extension to the system, that will enable the dissemination of training materials from centres to individuals in their home has been considered. This has been partially designed and implemented but it seems to be being overtaken by the rapid changes in telecommunications systems that is occurring at the present time. 
The East Midland region of England is being covered by an independent cable operator called Diamond Cable. As part of this service they offer some novel services that are of particular interest to the NewLink Project as a whole. The current plan for the NewLink Project is for between three and five centres to be linked together by a Diamond Cable service. In the first instance, this will enable cheaper inter-centre telephone communications and, the data on these systems will be transferred by traditional analog equipment ie: modems.

Each of these centres will use the existing CIAN system and act as a HUB to a selection of people in their locality. This HUB will both, supply them with work/training materials and, collect from them the work they have produced on their home computers. This will allow tutors or job allocators to be at any of the centres and for the work/training to be carried out by a wide pool of individuals spread out across the area, whilst the running cost of the operation is minimized.

Through this link there will be access to various electronic services. The most significant connection will undoubtedly be a link to the Internet.

\section{The Future}

The possibilities for the future extend well beyond the speed limitations imposed by this medium. Direct digital connections will be possible between each centre using ISDN technology. This will allow high rates of data exchange and thus bring new services such as video-conferencing and distance training etc.

At present NewLink is making cautious plans to enter this arena. We are concerned that our developments are accessible, affordable and transportable. The accessibility must place them into a particular educational and social context. The affordability must take into consideration the typical incomes of individuals and projects that work with people with physical disabilities.

The dream is that NewLink will significantly contribute to the inclusion of as many people with a physical disability as possible into the ever growing world of computer communications, and that this will assist them in being more fully included in society.

\section{Bibliography}

Barnes, K., R. W. Jotham, C. I. G. Sherman. 1994. Information Technology Training and Community Enterprise for people with a disability: Computer-Mediated Systems for Training and Enterprise. Submitted to the Journal of Microcomputer Applications.

Brodin, J., M. Magnusson. 1993. Videotelephony and Disability: A Bibliography. Department of Education, Stockholm University.

Jotham, R. W. 1992. The Impact of Computer Technology on the Vocational Situation of Disabled People. Computers for Handicapped Persons. Proceedings of the 3rd International Conference.

Wells, R. 1992. Computer-Mediated Communication for Distance Education: An International Review of Design, Teaching, and Institutional Issues. ACSDE, The Pennsylvania State Uni. 